\title{
1-D resistivity structures of the oceanic crust around the hydrothermal circulation system in the central Mariana Trough using Magnetometric Resistivity method
}

\author{
Noriko Tada $^{1}$, Nobukazu Seama ${ }^{2,1}$, Tada-nori Goto ${ }^{3}$, and Motoyuki Kido ${ }^{4}$ \\ ${ }^{1}$ Graduate School of Science and Technology, Kobe University, Kobe 657-8501, Japan \\ ${ }^{2}$ Research Center for Inland Seas, Kobe University, Kobe 657-8501, Japan \\ ${ }^{3}$ Japan Agency for Marine-Earth Science and Technology, Yokosuka 237-0061, Japan \\ ${ }^{4}$ Research Center for Prediction of Earthquakes and Volcanic Eruptions Graduate School of Science, \\ Tohoku University, Sendai 980-8578, Japan
}

(Received February 18, 2005; Revised May 30, 2005; Accepted May 31, 2005)

\begin{abstract}
We present preliminary results of an electromagnetic survey over a region of hydrothermal circulation in the spreading axis of the central Mariana Trough. The Magnetometric Resistivity (MMR) method is used to determine the electrical resistivity structure of the oceanic crust around the hydrothermal system. 1-D electrical resistivity structure is calculated from the relation between the amplitude of magnetic field and source-receiver separation. The amplitudes of magnetic field variation of ocean bottom magnetometers (OBMs) placed on axis are larger than those of OBMs about $700 \mathrm{~m}$ away from the spreading axis, for source-receiver separations larger than $400 \mathrm{~m}$. We estimated two resistivity structure models: one for the axial OBMs, and another for the offaxis OBMs. A region of lower resistivity between depths of 100-300 $\mathrm{m}$ is identified in the on-axis model. The hydrothermal source of the Alice Springs Field probably exists beneath the spreading axis, and the size of this source is smaller than $700 \mathrm{~m}$. Lower resistivities at a depth of $50 \mathrm{~m}$ are identified in both the on-axis and the off-axis models, suggesting that the porosity in the uppermost oceanic crust is largest at this depth.
\end{abstract}

Key words: Hydrothermal circulation system, resistivity structure, MMR method, the central Mariana Trough.

\section{Introduction}

Hydrothermal circulation is one of the most important seafloor processes of heat transfer, in which energy inside the earth is discharged into the ocean. Magma, which rises under the spreading axis to create new oceanic crust, loses energy through cooling by seawater. Seawater also promotes cooling the oceanic crust through penetration around the spreading axis, and such phenomenon is called the hydrothermal circulation. Understanding of the convection patterns in hydrothermal circulation can provide a deeper understanding into the discharge of energy at the spreading axis and cooling of the oceanic crust.

The Magnetometric Resistivity (MMR) method is one of the controlled source methods, which has been used to estimate electrical resistivity of the uppermost oceanic crust. The electrical resistivity of the oceanic crust is sensitive primarily to the amount of fluid within the crust, the distribution of the fluid, and its temperature and salinity. Because of this sensitivity, the electrical resistivity is used to infer the volume and temperature of hydrothermal circulation fluid in the shallow crust (Nobes et al., 1986, 1992; Evans et al., 1998, 2002). Nobes et al. $(1986,1992)$ conducted an MMR survey in the hydrothermally active Middle Valley off the Juan de Fuca Ridge. These were the first deep wa-

Copy right(c) The Society of Geomagnetism and Earth, Planetary and Space Sciences (SGEPSS); The Seismological Society of Japan; The Volcanological Society of Japan; The Geodetic Society of Japan; The Japanese Society for Planetary Sciences; TERRAPUB. ter applications of the technique. Evans et al. $(1998,2002)$ determined resistivity models at the depth up to $1 \mathrm{~km}$ beneath the seafloor both at the edge axis and further away. Resistivity models near the spreading axis have generally lower resistivity than those in the off-axis area. Evans $e t$ al. (1998) concluded that lower axial resistivities within the uppermost $600-800 \mathrm{~m}$ of crust are associated with a recent shallow dike intrusion event and subsequent high temperature fluid circulation at the Juan de Fuca Ridge. Evans et al. (2002) also explained the lower axial resistivities on the East Pacific Rise by the presence of hotter pore-fluids beneath the ridge crest.

In this paper, we report on results of our MMR experiment around a hydrothermal circulation vent on the spreading axis of the central Mariana Trough. First, we introduce our MMR experiment in detail. Then, we analyze the data obtained by this experiment and estimate one-dimensional (1-D) resistivity structures of the uppermost oceanic crust. Finally, we interpret the electrical resistivity structures in terms of hydrothermal circulation beneath the spreading axis of the central Mariana Trough.

\section{MMR Experiment}

We carried out an MMR experiment around the hydrothermal vent called Alice Springs Field $\left(18^{\circ} 12.9^{\prime} \mathrm{N}\right.$, $144^{\circ} 42.5^{\prime} \mathrm{E}$ and $3600 \mathrm{~m}$ deep) in the central Mariana Trough during R/V Kairei KR02-14 cruise (Seama et al., 2003). The relief in the Middle Valley is interpreted as a neovol- 
(a)

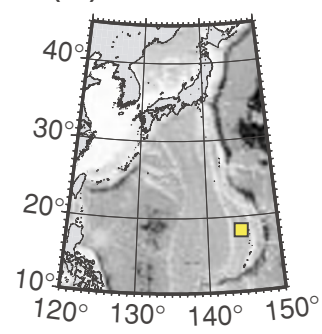

(b)

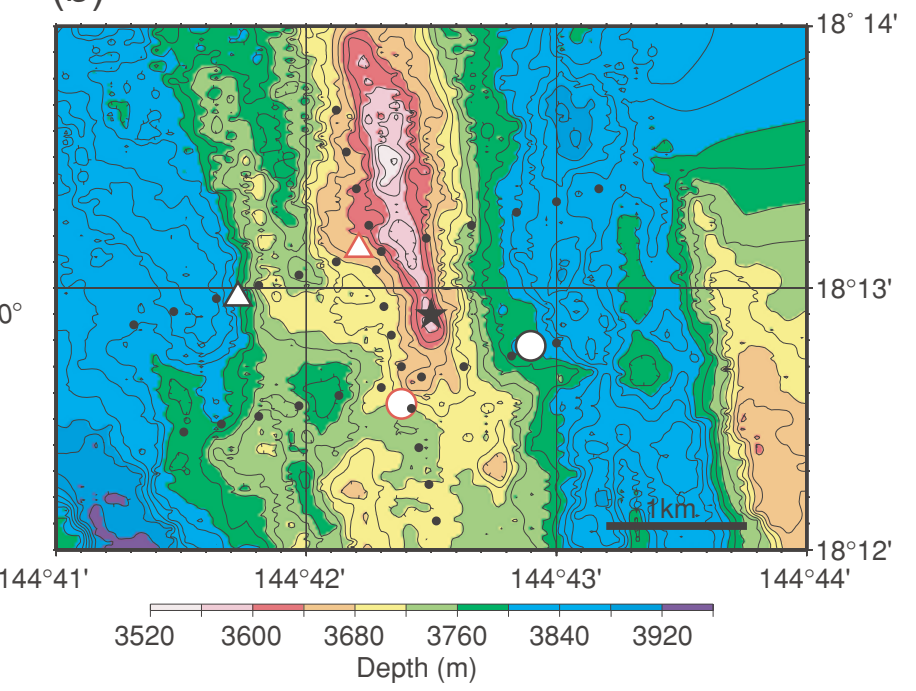

Fig. 1. (a) Location map of the Magnetometric Resistivity experiment (yellow square). (b) Bathymetry around the Alice Springs Field (star) in the central Mariana Trough. The contour interval is $20 \mathrm{~m}$. Locations of the two ocean bottom magnetometers (OBMs) on the spreading axis (red circle and triangle), the two OBMs off the axis (black circle and triangle), and 34 transmission stations (black dots) are shown.

canic ridge and corresponds to an active spreading axis. Alice Spring Field locates on this spreading axis (Fig. 1).

This hydrothermal activity was discovered by the submersible Alvin and the temperature of vent fluids were measured up to $285^{\circ} \mathrm{C}$ in 1987 (Craig et al., 1987). The activity of the Alice Springs Field has been monitored by 'Shinkai 6500' submersible dives; vent temperatures were $280^{\circ} \mathrm{C}$ and $264^{\circ} \mathrm{C}$ in 1992 (Gamo et al., 1994) and in 1996 (Fujikura et al., 1997), respectively.

The MMR method is a logistically simple magnetic technique to investigate of a shallow oceanic crust that involves two components: a vertical bipole electric current as a source; and separate ocean bottom magnetometers (OBMs) as receivers (Edwards et al., 1981). We used a newly developed MMR system (Seama et al., in prep.) in this experiment. Six OBMs were placed around the Alice Springs Field and four of them successfully recorded seafloor data: two OBMs were placed on the spreading axis about $700 \mathrm{~m}$ away from the Alice Springs Field, one OBM was placed on the eastern flank of the ridge, and one OBM, which was farther from the Alice Springs Field, was settled on the western flank of the ridge (Fig. 1). All OBMs were equipped with fluxgate sensors to measure the three-component of magnetic field at the seafloor and two-component tiltmeters to measure the attitude of the OBM (Seama et al., 2003). Magnetic field and tilt data were recorded at one second intervals. A transponder was also attached to each OBM, which enabled us to determine a precise location of OBM through acoustic ranging from the research vessel. Thirtyfour transmission stations were completed: twelve stations were on the spreading axis, and twenty-two stations were off-axis (Fig. 1). The vertical bipole source, which generated a rectangular wave-form with a period of $16 \mathrm{~s}$ and with a peak current of approximately $19 \mathrm{~A}$, was applied between electrodes at the sea-surface and on the end of the wire just above the seafloor. The ship was kept on each station for 30 minutes to allow stacking at the periodic wave signals, improving the signal to noise ratio. On completion of a station, the wire was wound up by about $100 \mathrm{~m}$, and the ship was moved to the next site. Once on a new station, the wire was set as vertically as possible before relowering it to the seafloor, so that the source was kept as a vertical bipole.

\section{Data Analysis}

The electrical resistivity of the seafloor is calculated from the relation between the amplitude of induced magnetic field and the source-receiver separation. In the presence of a layered Earth, the magnetic field generated by a bipole source is azimuthally symmetric and falls-off with distance from the source approximately as $1 / r^{2}$ (Edwards et al., 1981). Larger magnetic field amplitude represents smaller resistivity for a given separation. The depth of resolution of this technique is about $1 / 3$ the maximum source-receiver separation (Edwards et al., 1981). For the first step of our analysis, source-receiver separations are calculated for each OBM. Then, amplitudes of horizontal magnetic field are calculated from the three-component magnetic field data. Finally, 1-D resistivity structures are determined from the relation between the separations and the amplitudes.

The source-receiver separation is defined as horizontal distance between the OBM and the transmission station since the bipole source is nearly vertical. The transmission station is equivalent to ship position, navigated by Global Positioning System (GPS). Based on GPS data of the ship location, two standard deviations of the ship position from its mean during each transmission varies from 16 to $36 \mathrm{~m}$. The location of the OBM is estimated by acoustic ranging between the ship and a transponder equipped on the OBM.

Amplitudes of the horizontal magnetic field were determined for the transmission time-windows and normalized by the electrical current intensity of the vertical bipole source as follows. First, time series of three-component magnetic field during the operation (30 minutes) are picked. Second, the picked data sets of 30 minutes length are di- 


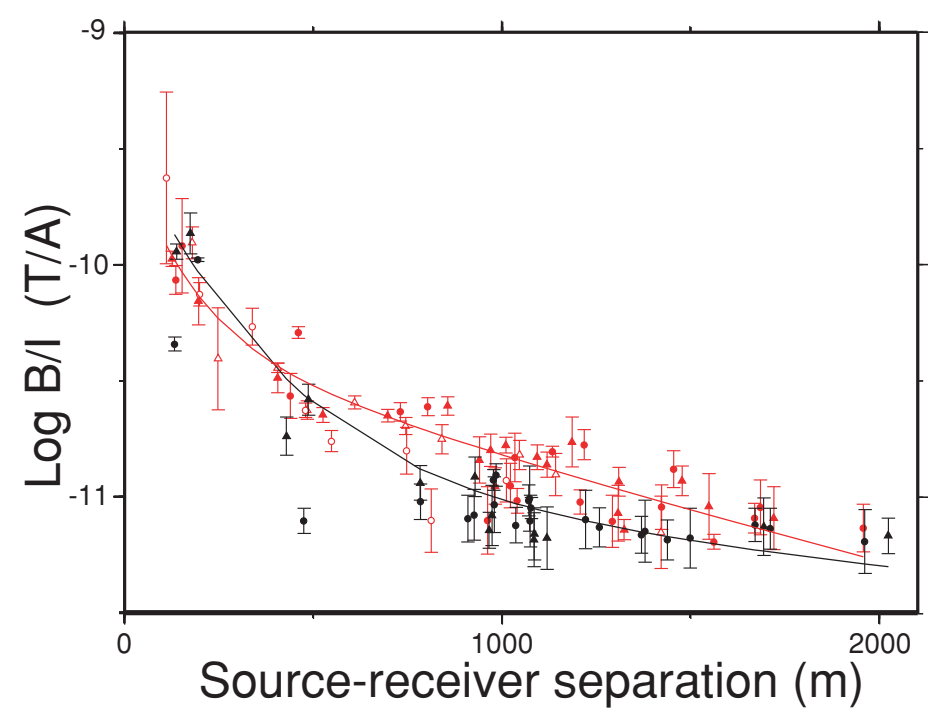

Fig. 2. Magnetic field amplitude data for all instruments. Amplitudes for each receiver (OBM) are shown using the same color symbol used for its location in Fig. 1, with red for the on-axis OBMs and black for the off-axis OBMs. In the on-axis OBMs, the data for the transmission stations on the spreading axis are plotted using opened circles and triangles, while the data for those off the spreading axis are plotted using solid circles and triangles. Error bars show two standard deviations (95\% confidence). The responses of the best-fitting model in Fig. 3(a) are plotted for comparison (solid curves).

vided into 13 segments of 256 seconds; the segments are overlapped by one half of their length (128 seconds) to make segments as many as possible. Third, the power spectrum was estimated by calculating the fast Fourier transform for each data segment. The amplitude of each data segment is examined by comparing this power spectrum with one from a reference rectangular wave with $1 \mathrm{nT}$ amplitude and a period of 16 seconds. Forth, the horizontal component of the magnetic field variation was separated from the vector magnetic field using the OBM attitude based on tiltmeter measurement. We did not use the vertical component because our assumptions are horizontally-layered Earth and vertical bipole source. Fifth, the horizontal component of the magnetic field was normalized by the current intensity of the vertical bipole source. Finally, the average and the standard deviation of the amplitude at each site were estimated from horizontal magnetic field data of the $13 \mathrm{seg}$ ments. The amplitude was regarded as data if it is larger than noise level. The noise level on each instrument was determined by analysis of non-transmission data windows and all noise levels are approximately $10^{-11.3} \mathrm{~T} / \mathrm{A}$.

1-D resistivity structure models were estimated from the relation between the source-receiver separations and the amplitudes of the horizontal magnetic field (Fig. 2) using the Occam inversion method (Constable et al., 1987) with a constraint that the resistivity varies smoothly with depth. We estimated two resistivity structure models from the amplitudes on axial OBMs (the on-axis model) and from those on off-axis OBMs about $700 \mathrm{~m}$ away from the axis (the off-axis model). Both axial OBMs show larger amplitudes of magnetic field variation than those on off-axis OBMs at source-receiver separations larger than about 400 m (Fig. 2). Amplitudes on axial OBMs are similar for all separations regardless of the direction of transmission; e.g. whether transmission is aligned along or across the spreading axis. Resistivity structure models can adequately ex-

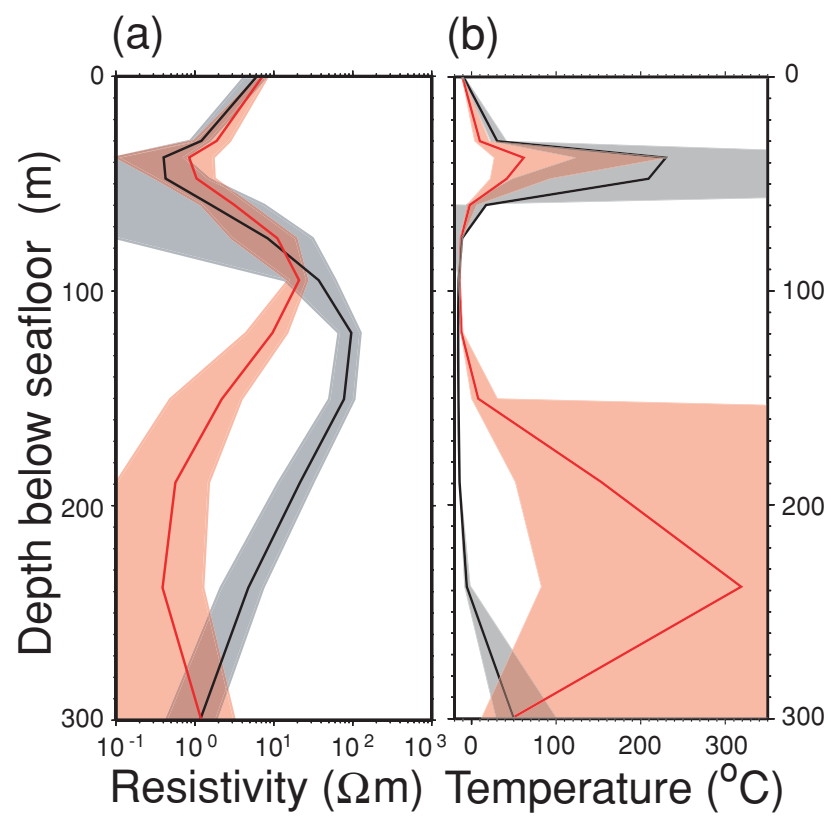

Fig. 3. (a) Resistivity models for the on-axis OBMs (red line) and the off-axis OBMs (black line). 95\% confidence regions of these models estimated using the jackknife method are also shown (shaded regions). (b) Temperature profiles of pore-fluid within the oceanic crust for the on-axis model (red line) and for the off-axis model (black line). 95\% confidences (shaded regions) are also shown.

plain the data, because response curves which are predicted from the on-axis model and the off-axis model estimated by the Occam's inversion are within the error bars of data (Fig. 2). The RMS misfits of the on-axis model and the offaxis model are 1.06 and 1.77 , respectively. $95 \%$ confidence limits of the resistivity structures (Fig. 3(a)) were estimated using the jackknife method, which calculates variances of the estimated values from datasets subdivided into $\mathrm{N}$ (the 
number of the whole data) groups of size $\mathrm{N}-1$ by deleting each data in turn from the whole data.

\section{Results and Discussion}

The on-axis model shows much lower resistivity than the off-axis model at depths between 100-300 m, while both the on-axis model and the off-axis model show similar resistivity at depths up to $100 \mathrm{~m}$ (Fig. 3(a)). The on-axis model has the lowest resistivity, $0.5 \Omega \mathrm{m}$, at a depth of $250 \mathrm{~m}$, and the resistivity in the deeper layers increases with depth. On the contrary, the off-axis has the highest resistivity, $100 \Omega \mathrm{m}$, at the depth of $120 \mathrm{~m}$, and the resistivity decreases with depth. In the uppermost $100 \mathrm{~m}$ beneath the seafloor, both the on-axis model and the off-axis model result in extremely similar structures; the $95 \%$ confidence zones of theses models are almost identical. At $50 \mathrm{~m}$ depth, both the on-axis and the off-axis models show low resistivity; the resistivities of both models overlap and are nearly $1 \Omega \mathrm{m}$.

The result that the on-axis model has lower resistivity than the off-axis model is consistent with the results of Evans et al. (1998, 2002). The resistivity of the on-axis model decreases greatly at a $100 \mathrm{~m}$ depth, corresponding to the axial structure of the Juan de Fuca Ridge (Evans et al., 1998). The resistivity of the off-axis model begins to decrease gradually at $130 \mathrm{~m}$ depth, which also agrees with the off-axis structure of both the Juan de Fuca Ridge (Evans et al., 1998) and the East Pacific Rise at $9^{\circ} 50^{\prime} \mathrm{N}$ (Evans et al., 2002). However, the trends of both the on-axis model and the off-axis model above $100 \mathrm{~m}$ depth are different from the resistivity structures of Evans et al. (1998, 2002). They show the resistivity structures increasing gradually from the seafloor down. On the contrary, the resistivity of both the on-axis model and the off-axis model in this study show a decrease in the depth range $0-50 \mathrm{~m}$, which indicates more detailed resistivity structure in the uppermost oceanic crust than that of Evans et al. $(1998,2002)$. One reason for this is that we recommend shorter source-receiver separations than did Evans et al. (1998, 2002).

The variation in electrical resistivity can be explained by differences in fluid temperature within the oceanic crust. Fluid temperature is estimated from the electrical resistivity by way of an empirical relationship, Archie's law (Archie, 1942),

$$
\rho_{m} / \rho_{f}=\Phi^{-t} .
$$

Here, $\rho_{m}$ is measured resistivity, $\Phi$ is porosity and $\rho_{f}$ is the resistivity of seawater. For a well-connected network of fluid-filled cracks, the exponent $t$ in Archie's law approaches 1.2 (Evans, 1994). The electrical resistivity of crustal fluid varies with pressure and fluid composition, especially with temperature. The fluid resistivity having a normal saline solution is $0.3 \Omega \mathrm{m}$ at fluid temperature of $2^{\circ} \mathrm{C}$. Nesbitt (1993) indicates that the resistivity decreases to the minimum of $0.04 \Omega \mathrm{m}$ at approximately $300^{\circ} \mathrm{C}$ as a result of increasing the ion mobility in water, when temperature of water increases. Seama and Matsubayashi (2003) approximate the resistivity of seawater with normal sea salinity as

$$
T=0.34 \sigma^{2}+4.2 \sigma-16
$$

where $\sigma$ is the conductivity (the inverse of the resistivity) and $T$ is the water temperature, up to $350^{\circ} \mathrm{C}$. The seawater temperature within the oceanic crust is estimated by the measured resistivity, Eqs. (1) and (2), assuming that the porosity can be inferred from another method. We apply this relation for the on-axis model and the off-axis model to estimate the water temperature. We used the porosity profile of Evans et al. (1998), which is calculated from the resistivity structures of the MMR experiment at the Juan de Fuca ridge on the condition that the porosity decreases with depth. This porosity is $17 \%$ at the top of the oceanic crust and decreases constantly to $14 \%$ at a depth of $300 \mathrm{~m}$. The on-axis temperature profile marks two peaks of high temperature, $60^{\circ} \mathrm{C}$ and $320^{\circ} \mathrm{C}$, at depths of $50 \mathrm{~m}$ and $250 \mathrm{~m}$, respectively (Fig. 3(b)). On the contrary, the off-axis temperature profile has only a peak of high temperature, about $230^{\circ} \mathrm{C}$, at a depth of $50 \mathrm{~m}$. The temperatures of both the onaxis and the off-axis temperature profiles deeper than 120 $\mathrm{m}$ indicate a significant difference. At $50 \mathrm{~m}$ depth, temperatures of these two models are considered to be same, because the resistivities of these models are indistinguishable within the 95\% confidence level (Fig. 3(a)). The temperature in the depth range $60-150 \mathrm{~m}$ of the off-axis profile indicates only very low values; values calculated show minus temperature, which probably results from the limitation of the empirical equation (2) which is available from $2^{\circ} \mathrm{C}$ to $350^{\circ} \mathrm{C}$.

The high temperature zone with the maximum temperature of $320^{\circ} \mathrm{C}$ at a depth of $250 \mathrm{~m}$ suggests the existence of hot pore-fluid, which is probably related to the Alice Springs Field hydrothermal circulation system located between the two axial OBMs. The hot pore-fluid is probably a source of the hydrothermal fluid observed at the vent by 'Shinkai 6500' submersible dives (Gamo et al., 1994; Fujikura et al., 1997). The hydrothermal source, however, does not exist beneath the off-axis OBMs about $700 \mathrm{~m}$ away from the spreading axis, because the temperature of the offaxis profile is nearly $0^{\circ} \mathrm{C}$ below $80 \mathrm{~m}$.

Since the temperature at a $50 \mathrm{~m}$ depth is unrealistically high, another explanation is required that the porosity at 50 $\mathrm{m}$ is larger than assumed. The bulk crustal porosity of Hole 504B of the Deep Sea Drilling Project at the Costa Rica Rift (Becker, 1985) is largest at a depth of $50 \mathrm{~m}$ and is about $2 \%$ larger than the porosity of the top of layer $2 \mathrm{~A}$. Since this depth accurately corresponds to the depth of low resistivities in both the on-axis and the off-axis models, the low resistivities at a depth of $50 \mathrm{~m}$ suggest larger porosity than values we used. If the porosity increases to $21 \%$ at $50 \mathrm{~m}$ (Becker, 1985), the minimum temperatures at the depth of $50 \mathrm{~m}$ are $10^{\circ} \mathrm{C}$ for the on-axis model and $27^{\circ} \mathrm{C}$ for the off-axis model. We consider that the porosity of this study area is higher than that of Hole 504B. Hole 504B is about 6 Ma crust (Becker, 1985) while this study area is almost $0 \mathrm{Ma}$. There is high correlation between the porosity and the permeability. The permeability of the young oceanic crust can range between $10^{-14}$ and $10^{-12} \mathrm{~m}^{2}$ and the permeability decreases with age (Fisher, 1998). In addition, layer $2 \mathrm{~A}$ is constructed from episodic lava flows and drain back-collapse features, means that porosity is highly heterogeneous. The increase of the porosity at 50 $\mathrm{m}$ is required for both the on-axis model and the off-axis 
model to get the normal temperature, suggesting that this high porosity layer occurs both on and off-axis.

\section{Conclusion}

Two resistivity models are estimated around the Alice Springs Field in the central Mariana Trough using the MMR method: the on-axis model beneath the spreading axis and the off-axis model beneath the seafloor about $700 \mathrm{~m}$ away from the spreading axis. Lower resistivities at depths from 100-300 $\mathrm{m}$ are identified beneath the spreading axis. This indicates the existence of hot pore-fluid which probably is a hydrothermal source of the Alice Springs Field beneath the spreading axis. The size of this source is smaller than 700 $\mathrm{m}$, and does not exist $700 \mathrm{~m}$ away from the spreading axis. The lower resistivities at $50 \mathrm{~m}$ depth are identified in both the on-axis model and the off-axis model, suggesting that the porosity in the uppermost oceanic crust is the largest at this depth.

Acknowledgments. We would like to thank scientific members, the captain, and the crew of the KR02-14 cruise (R/V Kairei, JAMSTEC) for their help. We are grateful to R. L. Evans for providing us the inversion code used for calculating 1-D resistivity structure and for careful check of the English style of this paper. We also thank two anonymous reviewers for their helpful comments which greatly improved the manuscript. This research was supported by Ministry of Education, Culture, Sports, Science \& Technology (MEXT), Japan through special coordination funds, 'Archaean Park Project' and 'The 21st Century COE Program of Origin and Evolution of Planetary Systems', and by Grant-in-Aid for Scientific Research (A)(2)(No. 14253003), Japan Society for the Promotion of Science (JSPS). GMT software (Wessel and Smith, 1998) is used to create figures.

\section{References}

Archie, G. E., The electrical resistivity log as an aid in determining some reservoir characteristics, J. Pet. Technol., 5, 1-8, 1942.

Becker, K., Large-scale electrical resistivity and bulk porosity of the oceanic crust, DSDP hole 504B, Cost-Rica rift, Initial rep. of Deep Sea Drill. Proj., 83, 419-427, 1985.

Constable, S. C., R. L. Parker, and C. G. Constable, Occam's inversion: A practical algorithm for generating smooth models from electromagnetic sounding data, Geophysics, 52, 289-300, 1987.

Craig, H., Y. Horibe, K. A. Farley, J. A. Welhan, K. R. Kim, and R. N. Hey, Hydrothermal vents in the Mariana Trough: Results of the first Alvin dives, EOS, Trans. Am. Geophys. Un., 68, 1531, 1987.
Edwards, R. N., L. K. Law, and J. M. DeLaurier, On measuring the electrical conductivity of the oceanic crust by a modified magnetometric resistivity method, J. Geophys. Res., 86, 11,609-11,615, 1981.

Evans, R. L., Constraints on the large-scale porosity and permeability structure of young oceanic crust from velocity and resistivity data, Geophys. J. Int., 119, 869-879, 1994.

Evans, R. L., S. C. Webb, M. Jegen, and K. Sananikone, Hydrothermal circulation at the Cleft-Vance overlapping spreading center: Results of a magnetometric resistivity survey, J. Geophys. Res., 103, 12,321-12,338, 1998.

Evans, R. L., S. C. Webb, and the RIFT-UMC Team, Crustal resistivity structure at $9^{\circ} 50^{\prime} \mathrm{N}$ on the East Pacific Rise: Results of an electromagnetic survey, Geophys. Res. Lett., 29, doi:10.1029/2001GL014106, 2002.

Fisher, A. T., Permeability within basaltic oceanic crust, Reviews of Geophysics, 36, 143-182, 1998.

Fujikura, K., T. Yamazaki, K. Hasegawa, U. Tsunogai, R. J. Stern, H. Ueno, H. Yamamoto, Y. Maki, S. Tsuchida, T. Kodera, H. Yamamoto, C. H. Sun, and T. Okutani, Biology and earth scientific investigation by the submersible "Shinkai 6500" system of deep-sea hydrothermal and lithosphere in the Mariana back-arc basin, JAMSTEC J. Deep Sea Res., 13, 1-20, 1997 (in Japanese with English abstract).

Gamo, T., H. Chiba, P. Fryer, J. Ishibashi, T. Ishii, L. E. Johnson, K. Kelly, H. Masuda, S. Ohta, A. L. Reysenbach, P. A. Rona, T. Shibata, J. Tamaoka, H. Tanaka, U. Tsunogai, T. Yamaguchi, and K. Fujioka, Mariana 1992 diving surveys by "Shinkai 6500" (Y9204 cruise): Revisits to the Mid-Mariana hydrothermal area and discovery of hydrothermal vents in the southern Mariana region, JAMSTEC J. Deep Sea Res., 10, 153-162, 1994 (in Japanese with English abstract).

Nesbitt, B. E., Electrical resistivities of crustal fluids, J. Geophys. Res., 98, 4301-4310, 1993.

Nobes, D. C., L. K. Law, and R. N. Edwards, The determination of resistivity and porosity of the sediment and fractured basalt layers near the Juan de Fuca Ridge, Geophys. J. R. astr. Soc., 86, 289-317, 1986.

Nobes, D. C., L. K. Law, and R. N. Edwards, Results of a sea-floor electromagnetic survey over a sedimented hydrothermal area on the Juan de Fuca Ridge, Geophys. J. Int., 110, 333-346, 1992.

Seama, N. and S. Matsubayashi, Recent progress in technology for marine geophysical research, Jour. Japan Soc. Mar. Surv. Tech., 15, 71-87, 2003 (in Japanese).

Seama, N., T. Goto, Y. Nogi, M. Ichiki, T. Kasaya, N. Tada, H. Iwamoto, K. Kitada, T. Matsuno, S. Yoshida, Y. Kawada, M. Ito, R. Ishii, K. Takizawa, K. Suyehiro, H. Utada, and M. Shimoizumi, Preliminary Report of KR02-14 Kairei cruise, JAMSTEC J. Deep Sea Res., 22, 89106, 2003.

Wessel, P. and W. H. Smith, New, improved version of the Generic Mapping Tools released, EOS Trans. Am. Geophys. Un., 79, 579, 1998.

N. Tada (e-mail: noriko@kobe-u.ac.jp), N. Seama, T. Goto, and M. Kido 